\title{
A superexploração do trabalho em economias periféricas dependentes
}

\author{
Marisa Silva Amaral \\ Universidade de São Paulo (USP)
}

\author{
Marcelo Dias Carcanholo \\ Universidade Federal Fluminense (UFF)
}

\begin{abstract}
A superexploração do trabalho em economias periféricas dependentes
Resumo: O presente artigo parte do escopo de análise da teoria marxista da dependência, que identifica a superexploração do trabalho como característica fundamental da condição dependente, fato este marcado pela intensificação do processo de transferência de valores produzidos na periferia e acumulados nos países do centro. Pretende demonstrar como o processo de acumulação de capital leva à formação de um exército industrial de reserva e como este último contribui com as formas de superexploração do trabalho e com o seu fortalecimento para o caso dos países dependentes, em especial os latino-americanos.

Palavras-chave: acumulação capitalista, exército de reserva, dependência, superexploração do trabalho.
\end{abstract}

\section{A Brief Review of the Content of Super-exploitation of Workers in Dependent Peripheral Economies} Abstract: This paper uses the Marxist theory of dependence, which identifies the super-exploitation of workers as an essential characteristic of the dependent condition, a fact that is marked by the intensification of the transfer of wealth produced in the periphery and accumulated in the countries of the center. It intends to demonstrate how capital accumulation leads to the formation of an industrial reserve army and how this contributes to the forms of super-exploitation of labor and to its strengthening in dependent countries, particularly those of Latin America.

Key words: capitalist accumulation, reserve army, dependence, super-exploitation of labor. 


\section{Introdução}

A teoria marxista da dependência entende a situação dependente como um condicionamento da economia de certos países em relação ao desenvolvimento e expansão de outras economias. Desta forma, os países dominantes poderiam se expandir e se auto-sustentar enquanto que os dependentes apenas poderiam fazê-lo como um reflexo da expansão dos anteriores (DOS SANTOS, 1970). Nos termos de MARINI (2000, p. 109), a dependência deve ser

[...] entendida como uma relação de subordinação entre nações formalmente independentes, em cujo âmbito as relações de produção das nações subordinadas são modificadas ou recriadas para assegurar a reprodução ampliada ${ }^{1}$ da dependência.

Analisando o processo de constituição da economia mundial que integra as economias nacionais ao mercado global, observa-se que as relações de produção são desiguais porque o desenvolvimento de certas partes do sistema ocorre às custas do subdesenvolvimento de outras. As relações tradicionais são baseadas no controle do mercado por parte das nações hegemônicas e isto leva à transferência do excedente gerado nos países dependentes para os países dominantes, tanto na forma de lucros quanto na forma de juros, ocasionando a perda de controle dos dependentes sobre seus recursos. E a geração deste excedente não se dá, nos países periféricos, por conta da criação de níveis avançados de tecnologia, mas através da superexploração da força de trabalho (MARINI, 1991).

Nessas circunstâncias, a acumulação de capital assume suas próprias características. Em primeiro lugar, ela é caracterizada por profundas diferenças em nível doméstico, no contexto local de um mercado de trabalho barato, combinado com uma tecnologia capital-intensiva. O resultado, sob o ponto de vista da mais valia relativa, é uma violenta exploração da força de trabalho, que se dá justamente como consequência do já mencionado intercâmbio desigual e dos mecanismos de transferência de valor que ele reforça. Ocorre que o resultado imediato destes mecanismos é uma forte saída estrutural de recursos, que traz consigo graves problemas de estrangulamento externo e restrições externas ao crescimento. E a única atitude que torna possível às economias periféricas garantir sua dinâmica interna de acumulação de capital é o aumento da produção de excedente através da superexploração da força de trabalho,

[...] o que implica no acréscimo da proporção excedente/ gastos com força de trabalho, ou, na elevação da taxa de maisvalia, seja por arrocho salarial e/ou extensão da jornada de trabalho, em associação com aumento da intensidade do trabalho(CARCANHOLO, 2004, p. 11).
Ou seja, a dinâmica do intercâmbio desigual culmina em superexploração e não em estruturas capazes de romper com os mecanismos de transferência de valor, e isto implica necessariamente numa distribuição regressiva de renda e riqueza e em todos os agravantes sociais já conhecidos deste processo.

Dadas estas características estruturais da dependência, a intenção é a de identificar, a partir daqui, os aspectos que explicam o recurso à superexploração do trabalho por parte da periferia para dar prosseguimento ao seu processo interno de acumulação. Ou, mais especificamente, o de perceber as relações existentes entre a superpopulação relativa e os mecanismos de superexploração do trabalho característicos da dependência e dos processos de transferência de valor (da periferia para o centro) que lhe são próprios.

\section{O tema da superexploração do trabalho e o exército industrial de reserva}

O tema da superexploração da força de trabalho, apontada por Marini (1991, p. 2000) como sendo a característica estrutural demarcadora da condição dependente vivida pelos países da periferia em relação aos países do centro do capitalismo mundial, guarda relação evidente com a lei geral da acumulação capitalista ${ }^{2}$ de Marx, especialmente quando são tratadas a funcionalidade do exército industrial de reserva para a acumulação capitalista e, ao contrário e muito mais importante, sua "disfuncionalidade" no que diz respeito aos impactos perniciosos que provoca em relação à classe trabalhadora em geral.

Tratando especificamente o tema da superexploração do trabalho, Marini nos mostra que sua ocorrência se dá em função da existência de mecanismos de transferência de valor entre as economias periférica e central ${ }^{3}$, levando a que a mais valia produzida na periferia seja apropriada e acumulada no centro. Configura-se, assim, uma espécie de "capitalismo incompleto" na periferia (aquilo que Marini chamou de "capitalismo sui generis"), justamente porque parte do excedente gerado nestes países é enviada para o centro - na forma de lucros, juros, patentes, royalties, deterioração dos termos de troca, dentre outras -, não sendo, portanto, realizada internamente. Então, os mecanismos de transferência de valor provocam, digamos assim, uma interrupção da acumulação interna de capital nos países dependentes que precisa ser completada e, para tanto, mais excedente precisa ser gerado. E esta expropriação de valor só pode ser compensada e incrementada no próprio plano da produção - justamente através da superexploração - e não no nível das relações de mercado, por meio de desenvolvimento da capacidade produtiva. Em outras palavras, 
[...] a apropriação de mais valia de um capital por outro não pode ser compensada pela produção de mais valia mediante a geração endógena de tecnologia pelo capital expropriado, estabelecendo-se, de maneira irrevogável, a necessidade da superexploração do trabalho(MARTINS, 1999, p. 128).

A explicação para este fato passa fundamentalmente pela análise da concorrência intrassetorial (dentro de um mesmo setor produtivo) e a da concorrência intersetorial (entre setores distintos de produção) e se articula necessariamente com a análise da tendência à queda da taxa de lucro ${ }^{4}$ - que, embora não seja tratada neste ensaio por absoluta falta de espaço, merece ser aqui pelo menos apontada, pois é o eixo através do qual se desenvolvem os tipos de concorrência antes mencionados.

Tratando primeiramente da concorrência intrassetorial, ocorre que o aumento da produtividade em determinado setor propicia, do ponto de vista de cada capitalista particular, a criação de mais produtos no mesmo espaço de tempo. Essa circunstância permite a este capitalista reduzir o valor individual de suas mercadorias a um nível inferior ao valor de mercado e, portanto, apropriar-se de uma mais valia extraordinária (ou superlucro), quando da realização destes produtos no mercado ${ }^{5}$. Considerando que o mesmo ocorra com cada capitalista separadamente, o aumento de produtividade - estimulado pela possibilidade de apropriação de superlucro - generalizar-se-ia no ramo de atividade, determinado até o ponto em que houvesse excesso de mercadorias e que, por isto, as mesmas tivessem seus preços rebaixados a um nível inferior ao de seus valores individuais, de modo a haver necessariamente uma queda na taxa de lucro para o conjunto deste mesmo setor.

Lançando mão de certa formalização para o entendimento desta ideia, temos que três empresas distintas (I, II e III) produzem uma mesma mercadoria $A\left(M_{A}\right)$ - e se encontram, portanto, no mesmo setor produtivo - com níveis distintos de produtividade, de modo que, para cada empresa, o tempo de trabalho necessário para a produção de $\mathrm{M}_{\mathrm{A}}$ não é o mesmo. Sendo assim, (I), (II) e (III) produzem valores (V) diferentes, sendo que estes valores são medidos em horas de trabalho, tal como segue:

$$
\left.\begin{array}{l}
\mathrm{V}_{(\mathrm{I})}=4 \text { horas } \\
\mathrm{V}_{(\mathrm{II})}=6 \text { horas } \\
\mathrm{V}_{(\mathrm{III})}=8 \text { horas }
\end{array}\right\} \begin{aligned}
& \mathrm{V}_{(\mathrm{I})}+\mathrm{V}_{(\mathrm{II})}+\mathrm{V}_{(\mathrm{III})}=18 \text { horas } \\
& \text { TTSN }=6 \text { horas }
\end{aligned}
$$

O valor total produzido neste setor é de 18 horas e o tempo de trabalho socialmente necessário (TTSN) ${ }^{6}$ para a produção de uma mercadoria é de 6 horas - correspondente à média do tempo total gasto por todas as empresas dentro deste mesmo setor. A empresa (I) é a mais produtiva, dado que despende menos tempo que as outras para produzir uma mercadoria. Tendo sido calculado o valor de mercado $\left(\mathrm{V}_{\mathrm{M}}\right)$ de uma mesma mercadoria $\left(\mathrm{M}_{\mathrm{A}}\right)$ em 6 horas (correspondentes ao TTSN), é possível afirmar que a empresa (I), portanto, se apropria de um valor superior àquele que produziu. Ou seja, ela produz uma mercadoria no valor de 4 horas, vende esta mercadoria pelo $\mathrm{V}_{\mathrm{M}}$ de 6 horas e, assim, apropria-se de um valor extra de 2 horas, sendo que estas últimas correspondem àquilo que Marx chamou de mais valia extraordinária, medida pelo valor de mercado subtraído dele o valor da mercadoria quando sai da empresa. A mais valia extra se dá, portanto, quando uma empresa se apropria de um valor superior ao que produziu. Seguindo a mesma ideia, a empresa (III) é a menos produtiva, com um TTSN de 8 horas, de modo que perde 2 horas em termos de valor, isto é, o valor que produz é maior que o $\mathrm{V}_{\mathrm{M}}$. A empresa (II) não tem do que se apropriar de forma extraordinária, haja vista que o valor que produz é exatamente igual ao valor de mercado de $\mathrm{A}$. Isso nos remete à primeira lei geral do processo de produção da riqueza apontada por Marx: por conta do processo de concorrência em busca da mais valia extra, as empresas procuram incessantemente aumentar sua produtividade, explicando-se, assim, a queda no $\mathrm{V}_{\mathrm{M}}$ das mercadorias e, por conseguinte, a queda na taxa de lucro das empresas pertencentes ao setor em questão.

O ponto crucial deste esquema está na noção de redistribuição que ele nos aponta. É possível notar, a partir do que foi dito, que os capitais mais produtivos se apropriam de um valor superior ao que produziram, sendo o contrário verdadeiro para o caso dos capitais menos produtivos. Ocorre que a apropriação se dá justamente como resultado de algo produzido anteriormente, ou seja, não é possível que um capital se aproprie de um valor que não foi gerado. Sendo assim, se um capital se apropria de um valor superior ao que produz, de um valor maior que a sua contribuição quando da formação da massa total de valor gerada, significa que, de outro lado, há um capital gerando um valor sem se apropriar dele, há um capital produzindo algo para que os outros capitais mais produtivos se apropriem.

Transpondo estes aspectos para o nível do comércio internacional, devemos agora tratar as empresas (I), (II) e (III) como pertencentes a países distintos. Deste modo, o capital (I), mais produtivo, deve ser entendido como pertencente a um país do centro do capitalismo mundial, o capital (III) precisa ser tratado como inserido em um país periférico, exatamente por ser o menos produtivo, e o capital (II) neutraliza-se diante das colocações que pretendemos realizar, porque produz valor idêntico ao valor de mercado de A, em nada contribuindo com o mecanismo de redistribuição ao qual nos referimos. 
Assim sendo, e recorrendo ao esquema proposto, ocorre que os países periféricos são aqueles que produzem mais valor ( 8 horas), tendo em vista que utilizam relativamente mais trabalho vivo do que trabalho morto no processo produtivo - e é justamente o trabalho vivo o único capaz de produzir riqueza nova. Contrariamente, os países centrais (mais produtivos), por utilizarem menos força de trabalho frente ao que utilizam em meios de produção - isto é, por terem alta composição orgânica do capital (c/v) -, geram menos valor (4 horas). Contraditoriamente, quando se atinge o nível da apropriação da riqueza gerada, o processo tendencial se dá de maneira inversa: os países periféricos, embora produzam mais valor, não se apropriam dele, pois são incapazes de produzir mercadorias cujo valor esteja abaixo de seu valor de mercado; são, portanto, incapazes de reduzir seu TTSN. Inversamente, os países centrais, embora produzam menos valor, garantem sua apropriação baseados num TTSN que se encontra abaixo da média do setor, estando, assim, abaixo do $\mathrm{V}_{\mathrm{M}}$ da mercadoria $\mathrm{A}$.

Assim, torna-se cabível afirmar que a apropriação empreendida por parte dos países centrais se dá justamente às custas da ausência de apropriação por parte dos periféricos. Se assim o é, parece-nos correto dizer que a periferia produz valor que não será apropriado por ela internamente, mas transferido para os países do centro e por eles acumulado.

O mesmo ocorre no nível da concorrência intersetorial. Recorrendo ao esquema marxista da transformação dos valores em preços de produção, e utilizando a fórmula $\mathrm{c}+\mathrm{v}+\mathrm{m}$ (onde $\mathrm{c}$ representa o capital constante, $\mathrm{v}$ representa o capital variável, $\mathrm{c}+\mathrm{v}$ expressa, portanto, o capital total investido e $\mathrm{m}$ diz respeito à mais valia resultante de um período produtivo), que nos mostra o valor (V) produzido ao final de cada estágio de produção, temos que três empresas distintas (I, II e III) produzem as mercadorias A $\left(\mathrm{M}_{\mathrm{A}}\right), \mathrm{B}$ $\left(\mathrm{M}_{\mathrm{B}}\right)$ e $\mathrm{C}\left(\mathrm{M}_{\mathrm{C}}\right)$, respectivamente - e se encontram, portanto, em diferentes setores produtivos. Elas o fazem com níveis distintos de produtividade, com uma mesma massa de capital total inicial de 100 unidades distribuídas entre capital constante e capital variável, de maneira diversa para cada empresa individualmente, dado que, como já dito, seus níveis de produtividade são igualmente distintos, ou, melhor dizendo, são empresas que se encontram em setores de diferentes níveis de produtividade, uns tecnologicamente mais avançados, outros não - e com uma taxa de mais valia (m') de $100 \%{ }^{7}$, da maneira que segue:
A empresa (I) se encontra, no caso, num setor tecnologicamente mais avançado e, portanto, mais produtivo, dado que a massa de capital constante investido (60 unidades) é superior à massa de capital variável (40 unidades), ou, em outras palavras, o gasto com MP é relativamente superior ao gasto com FT, de modo que a composição orgânica do capital (c/v) é mais elevada. Seguindo o mesmo raciocínio, a empresa (III) se estabelece num setor de mais baixa produtividade, tendo em vista que a massa de capital constante (40 unidades) é inferior à massa de capital variável (60 unidades), de tal forma que o dispêndio com FT supera em termos relativos o gasto com MP.

Como a produção de mais valor depende da utilização da força de trabalho no processo produtivo e, mais do que isto, só pode se dar por intermédio desta utilização, fica notório que a empresa (I), mais produtiva, aquela que utiliza uma menor massa relativa de trabalhadores no processo, é justamente a que produz menos valor $(60 \mathrm{c}+40 \mathrm{v}+40 \mathrm{~m}=140 \mathrm{~V})$. Contrariamente, a empresa (III), menos produtiva, gera mais valor $(40 \mathrm{c}+60 \mathrm{v}+60 \mathrm{~m}=160 \mathrm{~V})$, tendo em vista que a utilização de trabalho vivo é relativamente maior que a de trabalho morto e que, portanto, a massa de mais valia (m) gerada é superior. Então, a produção de valor se dá de maneira mais eficaz nas empresas menos produtivas, sendo o oposto igualmente verdadeiro. Esta é a conclusão parcial a que nos permite chegar o esquema proposto; parcial porque se limita à análise do valor gerado ao final de cada processo produtivo, ainda sem nenhuma referência a respeito de como se dá a apropriação deste excedente.

Partindo, então, para este nível de análise, temos que a taxa de lucro (l') é a própria mais valia, considerada em relação a todo o capital empregado (c + v), ou seja, em relação ao capital constante, somado ao capital variável - e não mais apenas ao trabalho vivo, como ocorria no caso da taxa de mais valia -, podendo ser expressa por l' $=\mathrm{m} / \mathrm{c}+\mathrm{v}$. Sendo assim, como consideramos que todas as empresas em seus respectivos ramos de atividade empregam um mesmo capital total de 100 unidades, as variações na taxa de lucro para cada empresa individualmente acompanham as modificações ocorridas em termos da mais valia produzida por cada uma destas empresas, de modo que aquelas mais produtivas têm taxa de lucro mais baixa e vice-versa. Esta diferenciação em termos de 1' estimula a concorrência entre os setores, de modo que capitais mais produtivos (capital I,

\begin{tabular}{lcccccccc}
\hline & $\mathbf{M}$ & $\mathbf{c}+\mathbf{v}$ & $\left.\mathbf{m} \mathbf{~}^{\prime}=\mathbf{m} / \mathbf{v}\right)$ & $\mathbf{m}$ & $\mathbf{V}$ & $\mathbf{l}$ & $\mathbf{P P}$ & PP $\mathbf{V}$ \\
(I) & $\mathrm{A}$ & $60 \mathrm{c}+40 \mathrm{v}=100$ & $100 \%$ & 40 & 140 & $40 \%$ & 150 & +10 \\
(II) & $\mathrm{B}$ & $50 \mathrm{c}+50 \mathrm{v}=100$ & $100 \%$ & 50 & 150 & $50 \%$ & 150 & 0 \\
(III) & $\mathrm{C}$ & $40 \mathrm{c}+60 \mathrm{v}=100$ & $100 \%$ & 60 & 160 & $60 \%$ & 150 & -10 \\
\hline
\end{tabular}

Elaborado pelos autores. 
por exemplo) se transferem para ramos de maior 1' (capital III, por exemplo). Ao fazê-lo, provocam a queda na taxa de lucro das empresas pertencentes a este último ramo e a elevação de sua própria taxa de lucro. Este movimento, por sua vez, faz com que os capitais menos produtivos, agora com l' mais baixa, transfiram-se para ramos mais produtivos, que conquistaram uma elevação em sua taxa de lucro. E esta oscilação segue continuamente até que os setores que competem entre si tenham sua 1' igualada ${ }^{8}$, cessando o estímulo que faz com que um capitalista vá de um setor para o outro.

Forma-se assim o lucro médio ${ }^{9}\left(1_{\mathrm{m}}\right)$, que é justamente resultado da média simples das taxas de lucro de cada empresa - considerando, ainda, que capitais de mesmo montante recebem o mesmo lucro médio. Como, no caso, a taxa de lucro média é de $50 \%$, o $1_{m}$ é, portanto, igual a 50. A partir disto são formados os preços de produção (PP) e, assim, nos aproximamos mais da questão sobre a forma como se dá a apropriação do valor gerado. O preço de produção reflete o preço contido na mercadoria quando ela sai da fábri$\mathrm{ca}^{10}$ e pode ser expresso por:

$$
\begin{aligned}
& \mathrm{PP}=\mathrm{c}+\mathrm{v}+1_{\mathrm{m}} \\
& \text { ou, alternativamente, } \mathrm{PP}=\mathrm{V}+1_{\mathrm{m}}-\mathrm{m}
\end{aligned}
$$

Daí, percebe-se que, como o capital total investido $(c+v)$ e o lucro médio $1_{m}$ são os mesmos para cada empresa de cada setor, seus preços de produção (PP) são exatamente iguais em 150 unidades. A partir disto podemos chegar à noção das diferenças em termos de apropriação da riqueza gerada, bastando, para tal, subtrair dos PP das mercadorias seus valores (V). O resultado desta matemática simples é o de que "uma parte das mercadorias se vende acima do valor na mesma medida em que a outra é vendida abaixo" (MARX, 1974, p. 179). Há, portanto, valor sendo produzido em (III) que não é acumulado dentro deste setor (que produz um valor de 160 unidades e só consegue realizar 150 unidades dadas pelo PP). Por outro lado, o setor (I) gera 140 unidades de valor e realiza 150 unidades dadas pelo PP. Então, recorrendo mais uma vez ao fato de que não é possível que um capital se aproprie de um valor que não foi gerado, as 10 unidades acumuladas em (I) só podem ser as mesmas 10 unidades expropriadas em (III). Esta ideia, novamente transposta para o nível do comércio internacional, leva-nos a afirmar, objetivamente, que a periferia (representada pelo setor III menos produtivo) produz valor que será apropriado nos países do centro (representados pelo setor I mais produtivo). Objetivamente, o que ocorre é que as economias dependentes acabam se especializando na produção de mercadorias com menor avanço tecnológico (dependência tecnológica) e, portanto, estão sujeitas, dada a lei tendencial de igualação das taxas de lucro, a esse tipo de transferência de valor em direção aos países centrais. Com isto, parece-nos irrevogável a visão de dependência desenvolvida por Marini (2000), como um processo que responde à lógica de acumulação global através da produção de valores na periferia que são apropriados no centro.

Adicionalmente, vale acrescentar que, quando se atinge o nível da concorrência intersetorial, é introduzida a ideia de progresso técnico, inserido e liderado por um capital individual pertencente ou vinculado de forma direta ou indireta ao setor produtor de bens de consumo de luxo. Este dinamismo se justifica pelo fato de que o setor produtor de bens-salário não tem capacidade de sustentar o progresso técnico incorporado, haja vista que induz a ganhos de produtividade e à intensificação do trabalho, que acabam por produzir, ao mesmo tempo, uma queda no capital variável (ou na quantidade de força de trabalho) empregado no processo produtivo em relação ao que se investe em capital constante (ou em meios de produção) e um excedente de mercadorias para o qual, consequentemente, não há demanda, tornandose de difícil realização no mercado. Ou seja, trata-se de um processo contraditório, que amplia a massa de mercadorias produzida ao mesmo tempo em que reduz a possibilidade de realização dessas mercadorias mediante a diminuição relativa de força de trabalho na estrutura produtiva.

Ao contrário, o setor produtor de bens luxuosos encontra a capacidade de sustentação do progresso técnico na própria perda de participação do capital variável no processo de produção. É justamente a força de trabalho empregada que constitui a demanda para produtos suntuários, de modo que o aumento de produtividade tem limites muito mais restritos de interferência na incorporação de progresso técnico por parte do setor produtor de bens de luxo do que por parte do setor produtor de bens-salário.

Introduzida esta ideia, ocorre que a concentração da produtividade (ampliação da composição orgânica do capital, c/v) no setor produtor de bens de luxo (e seus fornecedores de bens de capital) traz à tona a necessidade de se ampliar a escala de produção, a difusão tecnológica, o consumo de matérias-primas por parte deste setor e, na esteira deste processo, também o consumo de força de trabalho, ao mesmo tempo em que é limitada a capacidade de fornecimento de mercadorias por parte do setor produtor de bens-salário - mercadorias estas indispensáveis para a reprodução da força de trabalho, inclusive a utilizada na produção de bens luxuosos -, dados os diferenciais de produtividade existentes entre ambos os setores. Ou seja, como a produtividade no setor produtor de bens-salário é inferior àquela relativa ao setor produtor de bens de luxo, tendo em vista que a capacidade de incorporação tecnológica por parte daquele setor é bastante inferior à deste último, o primeiro 
é incapaz de produzir mercadorias em quantidade suficiente para repor as necessidades de reprodução dos trabalhadores incorporados ao segundo, mesmo que consiga baixar seus preços individuais a um nível inferior aos preços de mercado.

Sendo assim, os insumos fornecidos pelos produtores de bens-salário são depreciados e desvalorizados como consequência imediata de ampliações na produtividade, da concorrência e do consequente nivelamento da taxa de lucro entre capitais individuais neste setor. $\mathrm{O}$ que faz com que seja rompida a queda na taxa de lucro - verificada pela análise da concorrência intra-setorial - no setor produtor de bens luxuosos. Isto se explica pelo fato de que, ao cair o valor dos bens-salário, cai também o valor da força de trabalho empregada no setor de bens suntuosos, simplesmente porque a reprodução dos trabalhadores torna-se mais barata e uma parcela dos salários pode ser subtraída.

Verifica-se, assim, um aumento da mais valia relativa no setor de bens luxuosos, conseguido em detrimento do setor de composição orgânica mais baixa (o de bens-salário), que sofre perda da mais valia absoluta, gerada em função de ampliações na produtividade e na concorrência intrassetorial para este setor específico de produção. Isto conduz a uma situação na qual seus preços são fixados abaixo do valor de suas mercadorias e para a qual a única possibilidade de compensação é a de que os preços da força de trabalho sejam também fixados abaixo de seu valor. Então, a perda de mais valia absoluta no setor produtor de bens-salário só pode ser compensada pela exploração do trabalho justamente por conta dos encadeamentos que se dão a partir dos níveis de concorrência antes expostos, especialmente a concorrência que se dá entre setores distintos de produção. Sinteticamente, trata-se de um estado no qual são introduzidas, no espaço de circulação, inovações tecnológicas geradas por setores de composição orgânica mais elevada, de modo a estimular um crescimento da produtividade e uma depreciação das mercadorias nos setores de composição orgânica inferior, cuja perda de mais valia não pode então ser compensada por geração endógena de progresso técnico, mas sim pela superexploração do trabalho ${ }^{11}$.

Transportando estes aspectos para o nível das relações entre países ou regiões, podemos dizer que

[...] os países centrais passam a concentrar, em seu aparato produtivo, os elementos tecnológicos que articulam o crescimento da composição técnica e orgânica do capital que permitem o desdobramento internacional de D em D'. Os países dependentes são objeto dessa articulação e oferecem os elementos materiais para a especialização do centro através de sua integração à divisão internacional do trabalho. [...] Diferentemente dos países cen- trais, onde a relativa homogeneização da base tecnológica permite aos segmentos vinculados ao 'setor produtor de bens-salário' responder tecnologicamente às inovações introduzidas pelos segmentos vinculados ao consumo suntuário, criando as bases para um mercado de massas e para a indústria de bens de capital que alavancarão de forma orgânica a industrialização no centro; os países dependentes, ao se integrarem no mercado mundial, a partir de grandes desníveis tecnológicos, não poderão responder da mesma forma, recorrendo à superexploração do trabalho (MARINI, 2000, p. 127 , destaque dos autores).

Feitos estes esclarecimentos, há quatro formas principais de superexploração do trabalho - atuando de forma isolada ou combinada (e esta última parece ser a tendência) - que possibilitam a continuidade do processo de acumulação capitalista na periferia, quais sejam: a) o aumento da intensidade do trabalho; b) a prolongação da jornada de trabalho; c) a apropriação, por parte do capitalista, de parcela do fundo de consumo do trabalhador - então convertido em fundo de acumulação capitalista - valendo o comentário de que este mecanismo atua no sentido de criar "condiciones a través de las cuales el capital termina violando el valor de la fuerza de trabajo ${ }^{12 ، " ~(O S O R I O, ~ 2004, ~ p . ~ 95) ; ~}$ e d) a ampliação do valor da força de trabalho sem que seja pago o montante necessário para tal.

A primeira destas formas de superexploração denota que, numa jornada de trabalho constante, o trabalho é intensificado e o trabalhador passa a produzir mais valor num mesmo espaço de tempo. A segunda, reflete um aumento do tempo de trabalho excedente para além daquele necessário à reprodução do próprio operário, de modo que o mesmo "segue produzindo depois de ter criado um valor equivalente ao dos meios de subsistência para seu próprio consumo" (MARINI, 2000, p. 123). A terceira, representa um mecanismo através do qual a classe capitalista se vê fortalecida no sentido de impor uma queda nos salários a um nível inferior àquele correspondente ao valor da força de trabalho. A ampliação do EIR é um bom exemplo disto, dado que os trabalhadores empregados se submetem a uma situação de arrocho salarial, tendo em mente a existência de pressão por parte dos desempregados, que se sujeitariam a uma remuneração inferior em troca de trabalho. Finalmente, a quarta forma está relacionada à ideia de que a determinação do valor da força de trabalho é histórico-social e, com o avanço das forças produtivas e, portanto, das necessidades humanas, esse valor sobe e, se não é pago integralmente, temos uma nova forma de superexploração do trabalho.

Neste momento, é relevante dizer que os quatro mecanismos expostos têm como característica fundamental 
[...] o fato de que são negadas ao trabalhador as condições necessárias para repor o desgaste de sua força de trabalho: nos dois primeiros casos, porque ele é obrigado a um dispêndio de força de trabalho superior ao que deveria proporcionar normalmente, provocando-se assim seu esgotamento prematuro; no último, porque se retira dele inclusive a possibilidade de consumir o estritamente indispensável para conservar sua força de trabalho em estado normal (MARINI, 2000, p. 126).

Significa dizer, de maneira geral, que o trabalho se remunera abaixo de seu valor e isto, por si só, deixa patente a existência de superexploração.

Recuperados estes mecanismos, torna-se relevante, por fim, relacioná-los mais diretamente com a existência do exército industrial de reserva - abordado por Marx e brevemente reproduzido em nota anterior. Essa relação tem o intuito de completar os apontamentos feitos anteriormente, quando iniciamos o tratamento da superexploração em si e o de revitalizar a ideia de que a teoria marxista é indispensável ao tratamento da real dinâmica de funcionamento do sistema capitalista de produção e, consequentemente, da explicação dos fenômenos que configuram e caracterizam a condição dependente.

Relacionar o EIR com a superexploração significa mostrar sua ação no sentido de exacerbar as formas ou os mecanismos de extração de mais valia antes apontados. Sua atuação mais geral é a de fortalecer a ocorrência da superexploração do trabalho e, sendo assim, provoca impactos simultâneos sobre os mecanismos de extensão da jornada de trabalho, de intensificação do trabalho e de queda salarial. Logo, implica em elevação da taxa de mais valia $(\mathrm{m} / \mathrm{v})$ e consequente elevação da taxa de lucro (l'). Isto ocorre porque, como já dito, a existência de uma massa de trabalhadores, que se encontra excluída, às margens do mercado de trabalho (massa de desempregados), exerce uma pressão sobre aqueles trabalhadores que se encontram efetivamente empregados, forçando a que se submetam a todas as formas de superexploração existentes, sob pena de se verem substituídos e desempregados por "trabalhadores da reserva" num momento futuro. Ou seja, a oferta de trabalho é muito maior que a demanda, há trabalhadores desempregados (ou subempregados), vivendo em condições de pobreza inferiores às dos assalariados. Tudo isto cria, evidentemente, um ambiente de competição entre os próprios trabalhadores, cada qual na tentativa de se ver empregado, seja através de manutenção ou de ingresso no mercado de trabalho.

Com isso, fica clara a funcionalidade do EIR para a acumulação capitalista, que se sustenta justamente baseada na superexploração, tanto através de ampliação da mais valia absoluta quanto da mais valia relativa. Mais do que isto, esta é a tendência mesma do sistema capitalista: ampliar a composição do capital, engrossar a massa de trabalhadores que compõem o EIR para, com isso, ter as portas abertas à ampliação da superexploração baseada nos quatro mecanismos de extração citados e, consequentemente, para o fortalecimento da acumulação.

\section{Considerações finais}

Diante do que foi exposto, temos que a superexploração da força de trabalho é a característica estrutural que demarca a condição dependente de um país. Sua ocorrência se dá em função da existência de mecanismos de transferência de valor entre as economias periférica e central, levando a que a mais valia produzida na periferia seja apropriada e acumulada no centro. Isto configura uma espécie de "capitalismo incompleto" na periferia, por conta da interrupção de sua acumulação interna de capital, que só pode ser completada com a geração de mais excedente no próprio plano da produção, justamente através da superexploração do trabalho.

Vimos ainda que o funcionamento do sistema capitalista tem como lei geral uma produtividade crescente, ou, dito de outra maneira, este sistema demonstra uma tendência ao incremento da composição orgânica do capital, de modo que aumenta a massa de capital constante, relativamente à massa de capital variável. $\mathrm{O}$ impacto imediato deste movimento da acumulação capitalista é a formação de um exército industrial de reserva (EIR) que traz consigo a possibilidade crescente de exploração capitalista dos assalariados, seja em termos de extensão da jornada de trabalho, seja pela intensificação do tra- 
balho numa mesma jornada, seja, ainda, em termos de arrocho salarial.

Para além desta relação imediata entre a superexploração do trabalho e o EIR, está a relação entre o próprio EIR e a taxa de lucro. Ao permitir a aplicação de mecanismos intensificadores da superexploração do trabalho, a existência do EIR leva a que seja detida ou temporariamente paralisada a tendência à queda da taxa de lucro, tendo em vista que esta última será tanto maior quanto maior for a massa de mais valia e, portanto, os graus de expropriação do trabalho. Esta possibilidade de ampliação da taxa de lucro - que é o objetivo capitalista por excelência - acaba por reforçar e até mesmo justificar a ocorrência de superexploração e, portanto, a continuidade na formação da superpopulação relativa fortalecedora deste processo.

\section{Referências}

CARCANHOLO, M. D. Causa e formas de manifestação da crise: uma interpretação do debate marxista. 1996. Dissertação (Mestrado em Economia) - Universidade Federal Fluminense, Rio de Janeiro, 1996.

. Dialética do desenvolvimento periférico: dependência, superexploração da força de trabalho e alternativas de desenvolvimento. In: IV COLÓQUIO LATINO-AMERICANO DE ECONOMISTAS POLÍTICOS, 31 de outubro a 2 de novembro. Anais..., São Paulo, 2004.

DOS SANTOS, T. The Structure of Dependence. American Economic Review, New York, p. 231-236, May, 1970.

MARINI, R. M. Dialéctica de la dependência. México: Ediciones Era, 1991. 2000.

. Dialética da dependência. Petrópolis: Vozes,

MARTINS, C. E. Superexploração do Trabalho e Acumulação de Capital: reflexões teórico-metodológicas para uma economia política da dependência. Revista da Sociedade Brasileira de Economia Política, Rio de Janeiro, n. 5, p. 121-138, dez., 1999.

MARX, K. O Capital: crítica da economia política. Rio de Janeiro: Civilização Brasileira, 1974. 5 v.

OSORIO, J. Crítica de la economía vulgar-Reproducción del capital y dependencia. México: Grupo Editorial Miguel Angel Porrúa, jul. 2004.

\section{Notas}

1 Nos termos da teoria marxista, o esquema de reprodução simples envolve um departamento produtor de meios de produção e um produtor de bens de consumo e tem, como principal característica, o fato de que toda a mais valia, apropriada pelos capitalistas, é gasta em consumo improdutivo, ou seja, tudo o que é ganho é também gasto em bens de consumo. No caso do "esquema de reprodução ampliada", que envolve também os dois departamentos, o capitalista não mais irá gastar, sob a forma de consumo improdutivo, toda a mais valia de que se apropria. Estaúltima é repartida em duas frações, de modo que uma delas corresponde à demanda do capitalista por bens de consumo e a outra é reinvestida em capital constante e capital variável; é, em outras palavras, acumulada. Desta forma, o que de fundamental as torna distintas não é o valor que cada uma delas é capaz de produzir, mas sim o modo como se dá a realização deste valor. Para o entendimento mais detalhado destes esquemas, consultar Marx (1974), Livro II, Seção III.

2 Por falta de espaço, uma recuperação acerca do funcionamento da lei geral da acumulação capitalista de Marx foi por nós suprimida. Para nossos propósitos, vale apenas apontar que, o que Marx pretendia ao discutir a lógica desse processo era esclarecer que o sistema capitalista tem como lei geral uma produtividade crescente. A tendência é a de que a composição orgânica do capital aumente progressivamente e que, portanto, aumente a massa de capital constante relativamente à massa de capital variável, levando à formação de um exército industrial de reserva (EIR) como impacto da própria acumulação capitalista. Esta população excedente é produto necessário da acumulação e é, simultaneamente, sua própria alavanca, tornando-se condição fundamental de existência do próprio modo de produção capitalista.Adialética da questão - e isto é fundamental - está no fato de que, ao reproduzir este sistema e permitir que haja ampliação da riqueza ou do capital social, a população trabalhadora produz as condições que a tornam relativamente supérflua a este mesmo modo de produção. Significa dizer que, quando ocorre um incremento na composição do capital (é a própria tendência no capitalismo), deve ser ampliada a produtividade do trabalho como instrumento de intensificação do processo acumulativo, ao invés de ocorrer uma expansão nos níveis de contratação de trabalhadores, que possam ser incluídos no processo produtivo, operando os novos meios de produção e acrescentados neste mesmo processo. Então, amplia-se a quantidade de máquinas e equipamentos e a contratação de trabalhadores não acompanha esta ampliação. Para um aprofundamento na questão, consultar Marx (1974), Livro I, Capítulo XXIII.

3 Embora a existência do intercâmbio desigual se constitua, de fato, numa forma de exacerbar e fortalecer "a sede de acumulação" e a exploração do trabalho, que daí deriva, MARINI (2000, p. 124) nos mostra que "não é, a rigor, necessário que exista o intercâmbio desigual para que 
comecem a funcionar os mecanismos de extração de mais valia [...]; o simples fato da vinculação ao mercado mundial e a consequente conversão da produção de valores de uso à produção de valores de troca que implica, têm como resultado imediato desatar um elã de lucro que se torna tanto mais desenfreado quanto mais atrasado é o modo de produção existente."

4 À medida que se desenvolve o modo de produção capitalista, percebe-se-e isto já foi mencionado em nota anterior - que a classe capitalista tende a ampliar sua produtividade como forma de ampliar também a acumulação de capital, de modo a produzir mais mercadorias num mesmo espaço de tempo. Este aumento de produtividade se configura, em primeira instância, numa ampliação da relação entre meios de produção e força de trabalho (MP/FT), utilizados no processo produtivo. Isto significa dizer que a composição orgânica do capital, ou a relação entre capital constante (c) e capital variável (v) investidos, também se amplia, mesmo que seja em proporção menor que aquela outra. Em outras palavras, o que se percebe é uma maior participação de c em relação ao capital global - e, portanto, numa participação reduzida dos salários em relação a este último. E, como "a taxa de lucro é uma função da taxa de mais valia e da composição orgânica do capital, 'pressupondo uma taxa de mais valia constante', o crescimento da composição orgânica do capital leva necessariamente à queda da taxa de lucro. Esta é a lei da queda tendencial da taxa de lucro"'(CARCANHOLO, 1996, p. 15, destaque dos autores). Isto posto, vale lançar a ideia de que a ampliação da superpopulação relativa contribui para que haja elevação da taxa de lucro - contrariando sua tendência à queda-, de modo que este objetivo final justifica, do ponto de vista capitalista, os próprios mecanismos de superexploração fortalecedores do EIR, considerando que a possibilidade de auferir maiores lucros forma uma relação direta com a possibilidade de engrossar o exército de reserva e reforçar a expropriação do trabalho. Esta tendência à queda da taxa de lucro foi brilhantemente percebida por Marx e tratada em toda a Parte Terceira do Livro III de O Capital, sob a denominação de Lei da Queda Tendencial da Taxa de Lucro (LQTTL). Os fatores contrariantes a esta lei de tendência estão referidos no Capítulo XIV deste mesmo livro.

5 Ovalor individual refere-se à quantidade de trabalhonecessário para a produção de uma mercadoria numa empresa específica; o valor de mercado é a média de todos os valores individuais de todas as empresas conjuntamente (é o trabalho socialmente necessário); e a mais valia extraordinária é a diferença entre estes dois valores, quando de sua realização no mercado.

6 O TTSN diz respeito ao tempo que a sociedade gasta para produzir uma mercadoria e corresponde, portanto, ao valor (V)damesma.

7 Aqui convém lembrar que a mais valia é derivada do capital variável, do trabalho vivo empregado na produção de mercadorias, e apenas deste trabalho (ou deste capital), sendo expressa numa proporção dele. O que ocorre é que parte da jornada de trabalho do trabalhadoré voltada para a sua própria reprodução, produzindo um valor equivalente ao da FT e a outra parte, o trabalho excedente, destina-se ao capitalista, à produção de mais valia. Sendo assim, a mais valia é a parte excedente do trabalho vivo (ou do capital variável) da qual se apropriam os capitalistas e a taxa de mais valia (m') expressa exatamente a relação entre a mais valia e o capital variável (m/ v). Quando consideramos que a taxa de mais valiaé de $100 \%$, significa que, numa jornada de trabalho de 8 horas, 4 horas correspondem ao tempo de trabalho socialmente necessário para que a força de trabalho se reproduza e as outras 4 horas restantes dizem respeito ao trabalho excedente (através do qual o trabalhador gera mais valia) do qual se apropria o capitalista. Deste modo, o valor da mais valia produzida é, neste caso, exatamente igual ao valor da força de trabalho ou ao tempo que a mesma despende para fazer face às suas necessidades de autorreprodução.

8 O processo de igualação das taxas de lucro entre distintos setores também é uma lei tendencial de funcionamento da economia capitalista, sujeita, portanto, a todos os movimentos de contratendência que lhe são correlatos, como o processo de concentração/centralização do capital, por exemplo.

9 Vale ressaltar que o lucro médio deve ser entendido como tendência, porque é fruto (ou resultado) de uma outra tendência, que é a de que capitais com menor taxa de lucro se transfiram para ramos de atividade que apresentem uma l' maior e que, como tendência, pode não se confirmar, pode ser barrada por fatores contrariantes que evitem ou posterguem sua concretização.

10 Notemos que está excluída do PP a mais valia produzida, justamente porque esta corresponde à fatia da qual se apropria o capitalista. Ela apenas se inclui de maneira indireta na formação do referido preço, pois está embutida no ${ }_{\mathrm{m}}$ auferido por esse capitalista. Além disto, vale acrescentar que o PP não é correspondente ao preço de venda ou preço de mercado $\left(\mathrm{P}_{\mathrm{M}}\right)$, pois, se ambos fossem iguais, implicaria igualdade entre oferta e demanda, fato meramente casual na dinâmica capitalista. Então, as mercadorias não são vendidas pelos seus valores, embora estes expliquem seus preços de produção. Se assim fosse, estaria anulada toda a ideia de Marx a respeito da realização de um valor superior àquele que se tem quando do ingresso no processo produtivo. Os valores simplesmente regulam as oscilações dos preços de mercado, que, por sua vez, flutuam em torno dos valores.

11 E é justamente isto (a maior parte do aumento da produtividade num país ou região sendo explicada pela incorporação tecnológica produzida em outro país ou região) que "fundamenta o desenvolvimento dependente de uma região"(Ibidem,p. 126).

12 A efetiva queda no valor da força de trabalho e, portanto, a efetiva "violação" da troca de equivalentes, só pode se dar 
pelo aumento da produtividade nos setores produtores de bens-salário, fazendo com que os preços destes bens sejam reduzidos. Deste modo, a reprodução da força de trabalho torna-se mais barata (o proletariado consegue garantir sua subsistência gastando menos recursos) e, portanto, seu valor diminui, provocando queda nos salários e, consequentemente, aumento relativo da mais valia. Um arrocho salarial que se dê por outros motivos diferentes deste (o aumento do EIR, por exemplo) não implica em queda do valor da força de trabalho. Estas observações nos remetem, inclusive, a uma diferença crucial entre a exploração do trabalho predominante no centro e a exploração do trabalho que predomina na periferia. Osorio (2004, p. 94) nos mostra que, no primeiro caso, a “explotación se apoya en el 'aumento de la capacidad productiva', lo que puede alcanzarse respetando el valor de la fuerza de trabajo y propiciar mejores salários y mayor consumo" e que, no segundo caso, "las formas de explotación se sustentan em la violación del valor de la fuerza de trabajo." Esta observação não significa que a acumulação no centro e na periferia se deem exclusivamente destas formas; apenas que a superexploração da força de trabalho, nas economias dependentes, tende a se aprofundar por ser a alternativa de acumulação interna de capital, frente à transferência de valores produzidos na periferia e que são acumulados no centro da economia mundial.

\section{Marisa Silva Amaral}

ms.amaral1@uol.com.br

Mestre em Economia pelo Instituto de Economia da Universidade Federal de Uberlândia (IE/UFU)

Doutoranda em Economia das Instituições e do Desenvolvimento pela Faculdade de Economia, Administração e Contabilidade da Universidade de São Paulo (IPE/FEA/USP)

Orientadora: Leda Maria Paulani

\section{Marcelo Dias Carcanholo}

mdcarc@uol.com.br

Doutor em Economia pelo Instituto de Economia da Universidade Federal do Rio de Janeiro (IE/UFRJ) Professor da Faculdade de Economia da Universidade Federal Fluminense (UFF)

\section{USP}

\section{Faculdade de Economia Administração e Con- tabilidade}

Av. Professor Luciano Gualberto, 908

Cidade Universitária

Sao Paulo - São Paulo - Brasil

CEP: 05508-900

\section{UFF}

Faculdade de Economia

Rua Tiradentes, 17

Ingá

Niterói - Rio de Janeiro - Brasil

CEP: 24210-510 